\title{
Effect of Minerals on Intestinal IgA Production Using Deep Sea Water Drinks
}

\author{
Hisashi Shiraishi, ${ }^{* a, b}$ Maho Fujino, ${ }^{b}$ Naoki Shirakawa, ${ }^{b}$ Nanao Ishida, ${ }^{a, b}$ Hiroki Funato,${ }^{b}$ \\ Ayumu Hirata, ${ }^{b}$ Noriaki Abe ${ }^{a, b}$ Michiro Iizuka,${ }^{b}$ Kohei Jobu, ${ }^{b}$ Junko Yokota,${ }^{b}$ and \\ Mitsuhiko Miyamura ${ }^{a, b}$ \\ ${ }^{a}$ Kochi Medical Graduate School; 185-1 Kohasu, Oko-cho, Nankoku, Kochi 783-8505, Japan: and ${ }^{b}$ Department of \\ Pharmacy, Kochi Medical School Hospital; 185-1 Kohasu, Oko-cho, Nankoku, Kochi 783-8505, Japan. \\ Received March 24, 2017; accepted August 1, 2017
}

\begin{abstract}
Minerals are essential for life, as they are a vital part of protein constituents, enzyme cofactors, and other components in living organisms. Deep sea water is characterized by its cleanliness and stable low temperature, and its possible health- and medical benefits are being studied. However, no study has yet evaluated the physical properties of the numerous commercially available deep sea water products, which have varying water sources and production methods. We analyzed these products' mineral content and investigated their effect on living organism, focusing on immune functions, and investigated the relation between physiological immunoactivities and mineral intake. We qualitatively analyzed the mineral compositions of the deep sea water drinks and evaluated the drinks' physical properties using principal component analysis, a type of multivariate analysis, of their mineral content. We create an iron and copper-deficient rat model and administered deep sea water drinks for 8 weeks. We then measured their fecal immunoglobulin A (IgA) to evaluate immune function. Principal component analysis suggested that physical properties of deep sea water drinks could be determined by their sources. Administration of deep sea water drinks increased fecal IgA, thus tending to stimulate immune function, but the extent of this effect varied by drink. Of the minerals contained in deep sea water, iron showed positive correlations with the fecal IgA. The principal component analysis used in this study is suitable for evaluating deep sea water containing many minerals, and our results form a useful basis for comparative evaluations of deep sea water's bioactivity.
\end{abstract}

Key words deep sea water; immunoglobulin A (IgA); physicochemical characterization; mineral

Disruption of homeostasis in the mucosal tissue leads to diseases such as cancer and infection. ${ }^{1)}$ In humans, this homeostasis is maintained by epithelial barriers, as well as the immune system, which can be classified into the innate and adaptive systems. Immune homeostasis is established through the construction of higher-order immune networks between these systems. In the adaptive immune system, immunoglobulin A (IgA)-producing B lymphocytes (B cells) play an important role in maintaining homeostasis and defending the mucous membrane. Interleukin (IL)-17-producing $\mathrm{T}$ helper cells are ever-present in the mucous layer, and contribute to intestinal immunity as well. ${ }^{2,3)}$ In the intestine, homeostasis is maintained by an enormous number of gut flora. Intestinal IgA plays a crucial role in maintaining host-gut flora homeostasis, and is mostly produced $\mathrm{T}$ cell-dependently in Peyer's patch germinal centers. ${ }^{4)}$ Probiotics, vitamins, minerals, and other components are thought to be involved in the maintenance of intestinal immune balance homeostasis. ${ }^{5)}$

Aside from the intestinal immune system, general health maintenance in humans is greatly influenced by minerals. Balanced mineral intake is essential to the preservation of human health, and it is necessary to adjust the amount and method of mineral intake in pathological conditions that can disturb the body's mineral composition. The main sources of daily mineral intake are food and drinking water. The mineral composition of drinking water is therefore important to the body's mineral replenishment.

Deep sea water refers to water obtained from the layer of ocean at 200 mor deeper, which is less polluted than the sur- face sea water and possesses many notable features. Namely, deep sea water is characterized by its richness in mineral nutrients that are essential to vital activities, its cleanliness, as it experiences little exposure to chemical pollution from inland waters and atmosphere, as well as its stable low temperature, as there is little seasonal temperature variation at depth. Various studies are currently examining the balanced mineral and essential trace element content in deep sea water. Deep sea water has been confirmed to contain 60 or more minerals, including macroelements such as calcium, phosphorus, potassium, sulfur, chlorine, sodium, and magnesium, as well as microelements such as iron, zinc, copper, manganese, iodine, selenium, molybdenum, and cobalt. ${ }^{6}$ ) Consumption of deep sea water is considered effective for replenishing minerals in the body and thus preventing lifestyle-related diseases. In medicine and health, deep sea water has been reported to help maintain the cardiovascular system, ${ }^{7-9)}$ liver function, ${ }^{10)}$ metabolism ${ }^{11)}$ and bone metabolism. ${ }^{12)}$ Pharmacological effects have been reported, such as improvement in cases of atopic dermatitis $^{13)}$ and fatigue, ${ }^{14,15)}$ suppression of bowel diseases including duodenal ulcer, ${ }^{16)}$ and suppression of breast cancer metastasis. ${ }^{17)}$

Our group has also found that deep sea water is effective for improving dyslipidemia and arteriosclerosis, ${ }^{18,19)}$ which suggests deep sea water's utility as a stimulator of antioxidant system in the body. However, as there are many sources of deep sea water even in Japan alone, and commercially available deep sea waters differ in hardness and production methods, we consider it necessary to characterize their respective 
mineral compositions to distinguish the functionality of each type of water.

When rats are fed with a diet deficient in trace elements including iron and copper, the content of mineral components in the body decreases, ${ }^{20}$ ) not only the symptoms of anemia, lowering of hemoglobin value but also lipid metabolism is affected, It has been reported that various disorders are caused. $^{21)}$ Iron deficiency increases liver storage copper and copper deficiency increases liver storage iron. ${ }^{22}$ It is considered that the two mineral components of iron and copper are complementary in the living body. In addition, the influence on immunity is similar, and the two mineral components are involved in the reduction of $\mathrm{T}$ cell number and suppression of activity. $^{23)}$

Against this background, we investigated the relation between the mineral composition and immune-stimulating effects of various deep sea waters, using an animal model of pathology with iron and copper deficiency.

\section{MATERIALS AND METHODS}

Deep Sea Water Drinks Twenty-one types of deep sea water drinks with different hardness and production methods were used. Drinks were labeled from a to u. Production area, hardness, and hardness adjustment method of the deep sea water drinks are shown in Table 1.

\section{Evaluation of Properties of Deep Sea Water Drinks}

Qualitative Analysis of Each Mineral Ingredient

The drinks were assayed for 72 mineral ingredients using Shimadzu technique paste search Co., Ltd. inductive coupling plasma mass spectrometry (Agilent7700x, horse mackerel Lent technology Co., Ltd. Santa Clara City, CA, U.S.A.), inductive coupling plasma emission spectrometry (ICPS-8100, Shimadzu Corporation, Kyoto, Japan), ion chromatography analysis (HIC-20Avp, Shimadzu Corporation), as appropriate.
Influence of Deep Sea Water Drinks on Intestinal IgA Production in Rat Model of Iron and Copper Deficiency

Materials and Reagents

Based on physical property evaluation, seven deep sea water drinks (d: $-2.27-0.79, \mathrm{j}:-1.61-0.51, \mathrm{k}:-1.330 .09$, $\mathrm{n}:-0.400 .70$, o: $-0.09-1.24$, p: -0.966 .13 , r: $5.52-0.95$ ) were selected, considering the differences in Principal component (PC)1 (-2.3-5.5) and PC2 (-1.2-6.1) areas (Fig. 1) and differences in hardness $(28-1000 \mathrm{mg} / \mathrm{L})$. Iron and copper deficient diet (AIN93G Iron, copper-free diet (solidity) (Oriental Yeast Co., Ltd., Tokyo, Japan) was used. Other reagents were of the highest grade commercially available.

Animals

Male Wistar rats (Japan SLC Inc., Ltd.) were kept at $23 \pm 2^{\circ} \mathrm{C}$ for $6 \mathrm{~d}$ after initial purchase. The animal experiment received approval from the Kochi University Animal Experiment Committee and all guidelines on animal experimentation set by the Kochi University medical department were followed.

Preparation of Iron- and Copper-Deficient Rat Models

Iron- and copper-deficient rat models were prepared by administering the iron- and copper-deficient diet for 8 weeks. The deep sea water drinks were administered simultaneously for 8 weeks beginning with the start of the diet. Fecal samples were collected for each individual rat for $24 \mathrm{~h}$ after 8 weeks.

Measurement of IgA in Feces

After freeze-drying, $0.1 \mathrm{~g}$ of harvested feces was mixed with $1 \mathrm{~mL}$ of phosphate buffered saline (PBS) containing $50 \mathrm{~mm}$ ethylenediaminetetraacetic acid (EDTA), 1\% bovine serum albumin and phenylmethylsulfonyl fluoride (Wako Pure Chemical Industries, Ltd.), and centrifuged at $10000 \times \boldsymbol{g}$ for $20 \mathrm{~min}$. IgA remaining in supernatant after centrifugation was measuring using a Rat IgA ELISA Kit (Bethyl Laboratories, Inc., Montgomery, TX, U.S.A.).

Statistical Analysis Statistical evaluation was performed

Table 1. Water Hardness and Production Method of Various Deep Sea Water Drinks

\begin{tabular}{|c|c|c|c|}
\hline Sample No. & Production area & Hardness $(\mathrm{mg} / \mathrm{L})$ & Hardness adjustment method \\
\hline $\mathrm{a}$ & A & 0 & Nothing added \\
\hline $\mathrm{b}$ & A & 10 & Bittern derived from DSW and Ca derived from DSW added \\
\hline $\mathrm{c}$ & A & 15 & Raw DSW added to desalinated water \\
\hline d & A & 28 & Add residual concentration water at dechlorination to desalinated water \\
\hline e & A & 50 & Add residual concentration water at dechlorination to desalinated water \\
\hline $\mathrm{f}$ & $\mathrm{B}$ & 50 & Highly concentrated mineral water from DSW added \\
\hline $\mathrm{g}$ & A & 76 & Raw DSW added to desalinated water \\
\hline $\mathrm{h}$ & A & 76 & Raw DSW added to desalinated water \\
\hline $\mathrm{i}$ & A & 88 & Bittern derived from DSW added to desalinated water \\
\hline $\mathrm{j}$ & A & 88 & Bittern derived from DSW added to desalinated water \\
\hline $\mathrm{k}$ & A & 100 & Bittern derived from DSW and Ca derived from DSW added \\
\hline 1 & A & 120 & Bittern derived from DSW and Ca derived from DSW added \\
\hline $\mathrm{m}$ & $\mathrm{C}$ & 150 & Bittern derived from DSW added \\
\hline $\mathrm{n}$ & A & 250 & Bittern derived from DSW and Ca derived from DSW added \\
\hline o & $\mathrm{C}$ & 250 & Bittern derived from DSW added \\
\hline $\mathrm{p}$ & $\mathrm{B}$ & 300 & Highly concentrated mineral water from DSW added \\
\hline $\mathrm{q}$ & A & 500 & Bittern derived from DSW and Ca derived from DSW added \\
\hline $\mathrm{r}$ & A & 1000 & Bittern derived from DSW and Ca derived from DSW added \\
\hline $\mathrm{S}$ & $\mathrm{C}$ & 1000 & Bittern derived from DSW added \\
\hline $\mathrm{t}$ & A & 1200 & Bittern derived from DSW and Ca derived from DSW added \\
\hline $\mathrm{u}$ & A & 1500 & Bittern derived from DSW and Ca derived from DSW added \\
\hline
\end{tabular}

DSW: Deep Sea Water. 


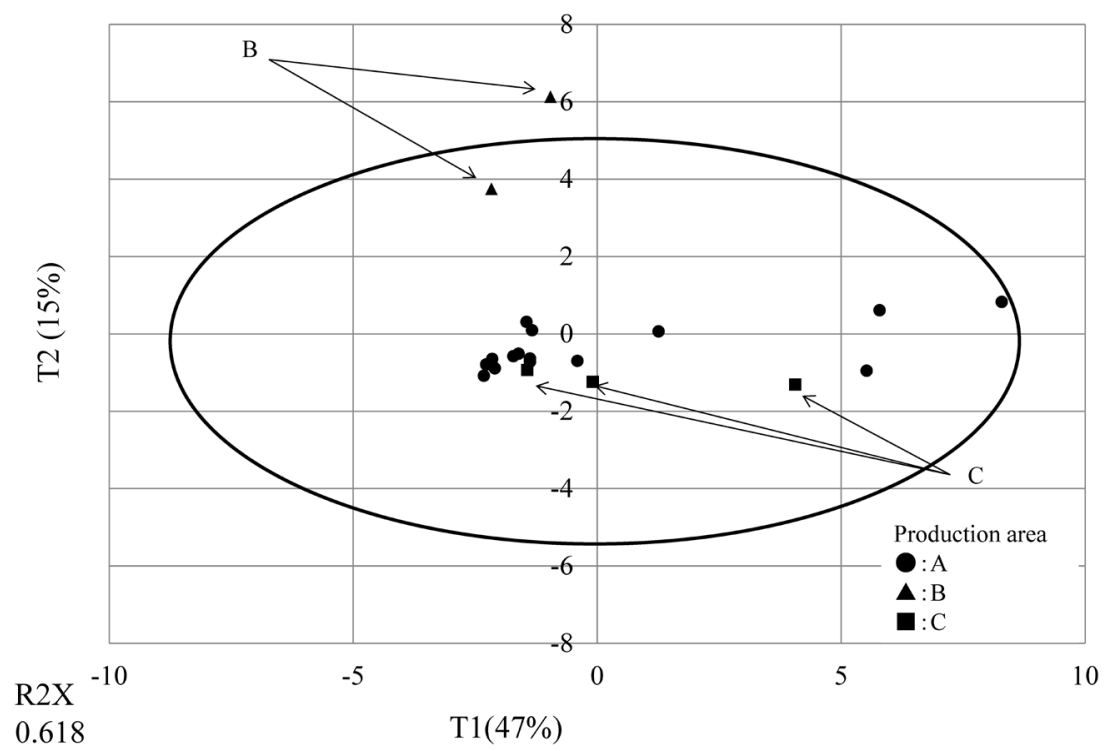

Fig. 1. Principal Component Analysis Scores Plot Based on Qualitative Data

using $\mathrm{R}$ Version 4.1 with $p<0.05$ considered to indicate significance. Principal component analysis (PCA) and orthogonal partial least squares discriminant analysis (OPLS-DA) were performed as multivariate analysis. The correlation test was conducted by Pearson's moment correlation analysis. Differences in fecal IgA concentrations in each group were made by multiple comparisons by the Bonferroni method.

\section{RESULTS}

Qualitative Analysis of Mineral Composition Of the 72 minerals assayed for, 32 were present in quantities above the detection level. Some minerals were only present in quantity above the detection threshold for water taken from particular sources, for instance, selenium at source A, manganese at source $B$, and vanadium at source $C$.

Principal Component Analysis of Mineral Compositions Principal component analysis was performed on 21 of the minerals detected in the tested drinks as a result of the qualitative analysis, revealing a contribution rate of $61.8 \%$ (Fig. 1). Drinks from source B were limited to PC2: 3.7-6.1, and others drinks were limited to PC2: $-2-1$. In source B contained zinc much compared with other groups. Zinc was plotted above the PC 2 axis because zinc is a mineral with a large factor loading in the positive direction with respect to PC 2 axis. Drinks from source $C$ was influenced by minerals with a large factor load in the negative direction of the PC 2 axis such as vanadium detected only with $\mathrm{C}$, and was plotted below the PC 2 axis. Calcium and magnesium both contribute to hardness and were loaded highly on PC1; hard waters were thus plotted in the positive area of PC1. Drinks with the same water source were plotted close to each other.

\section{Effects of Deep Sea Water on Intestinal Immunity}

IgA Concentration

Seven deep sea water-derived drinks were selected based on principal component analysis result: $d, j, k, n, o, p$, and $r$. Rats' fecal IgA concentration was lower in the negative controls that received distilled water compared to the deep sea water drink group (data not shown). Comparison within the deep sea water group revealed a trend of lower $\operatorname{Ig} \mathrm{A}$ values for

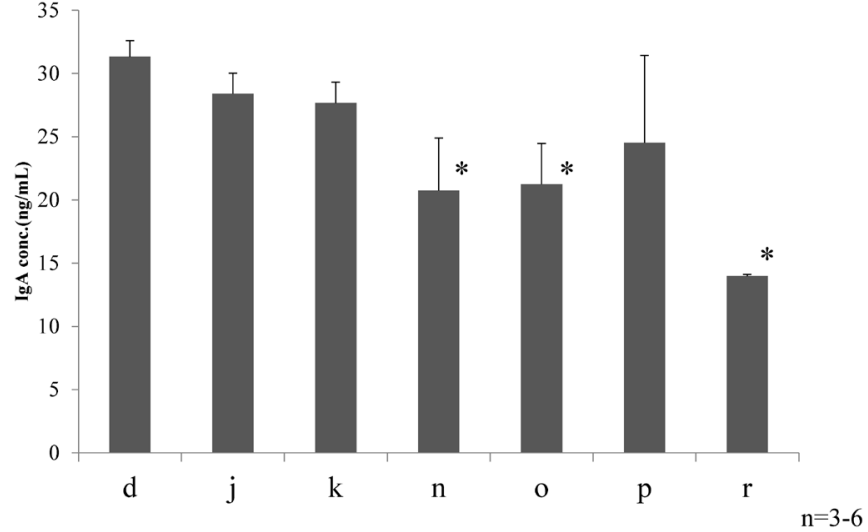

Fig. 2. Fecal IgA Concentration in Rats on Iron and Copper-Deficient Diet and Administered Various Deep Sea Water Drinks

Results are expressed as the mean \pm S.E. of the data from six animals. $* p<0.05$, $* * p<0.01$ compared multiple (ANOVA followed by Bonferroni method).

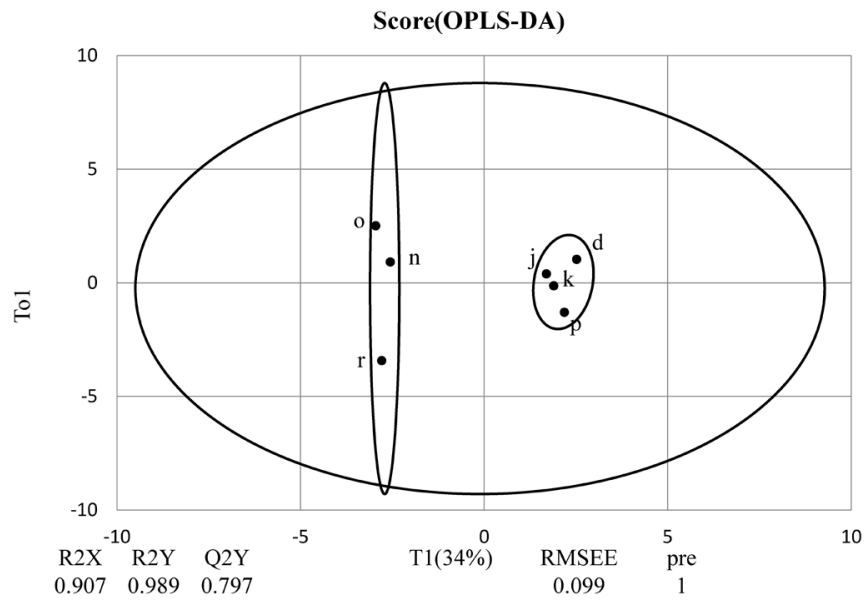

Fig. 3. OPLS-DA Scores Plot Based on Qualitative Analysis Data and IgA Concentration

those drinks that were plotted further into the positive region of PC1. We performed discriminant analysis to identify the minerals in deep sea water drinks that contribute to the dif- 


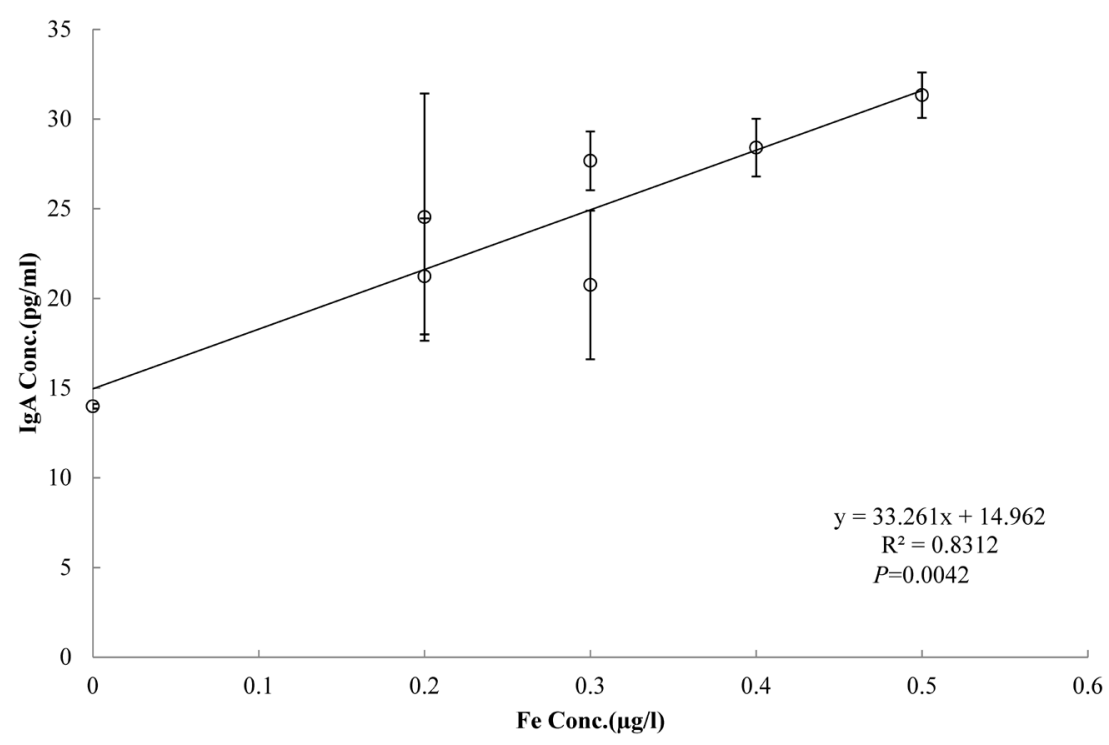

Fig. 4. Correlation between Iron Concentration and Fecal IgA in Each Deep Sea Water Drink

Pearson's moment correlation analysis was used to test for the presence or absence of correlation.

ferences in the IgA-producing ability. We conducted multiple comparisons by the Bonferroni method, divided the drinks into high fecal $\operatorname{IgA}$ group (d, j, k, p) and low group (n, o, r), and then performed orthogonal projections to latent structures discriminant analysis (Fig. 2). R2 value was 0.989 and Q2 0.797 (Fig. 3). The two groups were clearly distinguished. Evaluation of the relation between the fecal IgA concentrations and deep sea water drinks' mineral components revealed that out of the 32 minerals detected, only iron was positively correlated with fecal IgA (Fig. 4).

\section{DISCUSSION}

In this study, we performed a comprehensive mineral composition analysis on commercial deep sea water-derived drinks and investigated the effect of these drinks on intestinal immunity in an animal model of iron and copper deficiency. We analyzed the drinks for the presence of 72 minerals, and found that 32 minerals were present in detectable quantities. Principal component analysis with the mineral content as variables allowed for visual analysis of the differences in mineral content by water source. Principal component analysis is a method for summarizing the information contained in multiple dimensions to a reduced dimension, and is used in the search for diagnostic markers, root cause analyses of diseases, and quality evaluations of foods and crude drugs. Principal component analysis is also suitable for evaluating deep sea water drinks.

Possible effects on intestinal immunity were studied by collecting the feces of the pathological model animals and measuring $\operatorname{Ig}$ A content. IgA has been studied extensively as an intestinal immunity index. Various stimuli, such as microbes, can induce release of $\mathrm{T}$ cell-dependent IgA from Peyer's patches. ${ }^{4)}$ Once secreted into the intestinal lumen via the epithelium, $\operatorname{Ig}$ A reacts to exogenous antigens such as gut flora to modulate their impact on the body. T helper cells, which play central roles in the immune response, are present in Peyer's patches. $\mathrm{T}$ helper cells are classified into four types (Th1, Th2, Th17, and Treg) depending on the cytokines they pro- duce. These cells maintain immune homeostasis by exerting controls over each other. ${ }^{24,25)}$ We used seven kinds of drinks based on principal component analysis using iron and copper deficiency disease model rats, and evaluated the influence on immunity using $\operatorname{IgA}$ in feces as an indicator. The iron and copper deficiency disease model was administered iron and copper deficient diet for 8 weeks, and various deep sea water drinks were administered. In previous studies, mineral deficient pathological animals were produced at $4-8$ weeks ${ }^{26,27)}$ and beverages were evaluated at $4-12$ weeks. ${ }^{28,29)}$ In this mineral deficiency pathogenesis model, significant pathological weight loss was observed in disease model rats compared with normal rats over 8 to 12 weeks. Considering that continuation for 12 weeks is highly invasive to experimental animals, contrary to the animal experiment guidelines, the administration period was set to 8 weeks.

Compared to healthy animals, iron and copper-deficient negative controls were found to have lower fecal $\operatorname{IgA}$ value (data not shown). Iron and copper are essential for maintaining homeostasis in the body and also play important roles in immunomodulation, which is likely why negative controls showed diminished IgA. Furthermore, all deep sea wateradministered iron and copper-deficient animals showed higher fecal IgA levels compared to their negative-control counterparts, regardless of the types of deep sea water administered.

We performed OPLS-DA to identify the mineral component in deep sea water contributing to this effect and successfully divided the drinks into groups that resulted in high- and low fecal IgA concentrations. In mineral containing deep sea water drink, the mineral component showing a statistically significant positive correlation with fecal $\operatorname{IgA}$ concentration is only iron, and this time iron has the most influence on intestinal immunity in iron/copper deficiency pathology I guessed. The standard error of the group $r$ was smaller than that of the other groups. The reason for this is presumed that deep sea water drinks drunk in group $r$ were due to the iron concentration considered to have the most influence on intestinal tract IgA concentration was below the detection limit. The mucosal immune system is modulated through the interactions of vari- 
ous immune system-related cells. Recent studies have reported that increased $\operatorname{Ig} \mathrm{A}$ is the result of enhanced immune response due to activated antigen-presenting cells and lymphocytes. ${ }^{30)}$ Iron deficiency is associated with diminished number of $\mathrm{T}$ cells, decreases in IL-2 secretion, macrophage migrationinhibitory factor production and neutrophils, and lower NK cell activity. ${ }^{31)}$ In particular, in cases of iron deficiency, IL-6 reduction has been reported immunologically. ${ }^{32)}$ In the production of $\operatorname{IgA}$, the action of Th2 cells is involved, and the IgA-producing plasma cells differentiate under the stimulation of IL- 5 and IL- 6 produced by Th2 cells. Decrease in IL-6 is thought to indicate a decrease in function of Th2 cells, and even in the pathology model used this time, functional deterioration of Th2 cells leads to a decrease in IgA concentration, supplementation of iron component by deep sea water drinks I believe that the reduction of intestinal tract IgA concentration was suppressed. However, even in the drinking water $r$ in which the iron concentration was below the detection limit, the $\operatorname{Ig} \mathrm{A}$ concentration in the feces shows higher than the negative control, so the mineral component affecting the IgA concentration in the intestinal tract in the iron/copper deficiency disease model is I guess that it is not just iron.

The immunomodulatory effects reported thus far for deep sea water are immunosuppressive effects, as in anti-allergy effects, ${ }^{33)}$ and immune system stimulation following increased serum $\operatorname{IgG}$ value. ${ }^{34)}$ Both effects are thought to be caused by the minerals contained in deep sea water. These results add new knowledge to deep sea water's immune system-related functions via the augmentation of IgA secretion; this could be considered as an activation of the adaptive immune defense's humoral response caused by deep sea water.Further research is needed on the relation between Peyer's patch immune function control and minerals. Furthermore, it is necessary to elucidate the overall picture of the immune system in Peyer's patches via the minerals' ability to regulate biological functions through identifying the target immunocompetent cells, the receptors thereof and their subsequent actions.

Acknowledgment We appreciate the support of the Kochi Prefecture Muroto Deep Sea Water Functional Assessment Project in this research.

Conflict of Interest The authors declare no conflict of interest.

Supplementary Materials The online version of this article contains supplementary materials.

\section{REFERENCES}

1) Kawamoto $S$, Maruya M, Kato LM, Suda W, Atarashi K, Doi $Y$, Tsutsui Y, Qin H, Honda K, Okada T, Hattori M, Fagarasan S. Foxp3 $^{+}$T Cells regulate immunoglobulin A selection and facilitate diversification of bacterial species responsible for immune homeostasis. Immunity, 41, 152-165 (2014).

2) Shulzhenko N, Morgun A, Hsiao W, Battle M, Yao M, Gavrilova O, Orandle M, Mayer L, Macpherson AJ, McCoy KD, Fraser-Liggett C, Matzinger P. Crosstalk between B lymphocytes, microbiota and the intestinal epithelium governs immunity versus metabolism in the gut. Nat. Med., 17, 1585-1593 (2011).

3) Korn T, Bettelli E, Oukka M, Kuchroo VK. IL-17 and Th17 cells. Annu. Rev. Immunol., 27, 485-517 (2009).
4) Fagarasan S, Kawamoto S, Kanagawa O, Suzuki K. Adaptive immune regulation in the gut: $\mathrm{T}$ cell-dependent and $\mathrm{T}$ cell-independent IgA synthesis. Annu. Rev. Immunol., 28, 243-273 (2010).

5) Kaminogawa S. Effects of food components on intestinal flora, intestinal immune system and their mutualism. Bioscience Microflira, 29, 69-82 (2010).

6) Miyagi K, Kinjyo T, Taira M, Shingaki Y, Toguchi A, Kinjyo K, Sonan M. Study of medical treatment by deep sea water. Journal of the Society Tropical Resources Technologists, 12, 17-18 (1996).

7) Tsuchiya Y, Watanabe A, Fujisawa N, Kaneko T, Ishizu T, Fujimoto T, Nakamura K, Yamamoto M. Effects of desalted deep seawater on hematologic and blood chemical values in mice. Tohoku J. Exp. Med., 203, 175-182 (2004).

8) Sheu MJ, Chou PY, Lin WH, Pan CH, Chien YC, Chung YL, Liu FC, Wu CH. Deep sea water modulates blood pressure and exhibits hypolipidemic effects via the AMPK-ACC pathway: an in vivo study. Mar. Drugs, 11, 2183-2202 (2013).

9) Katsuda S, Yasukawa T, Nakagawa K, Miyake M, Yamasaki M, Katahira K, Mohri M, Shimizu T, Hazama A. Deep-sea water improves cardiovascular hemodynamics in Kurosawa and KusanagiHypercholesterolemic (KHC) rabbits. Biol. Pharm. Bull., 31, 38-44 (2008).

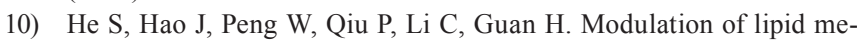
tabolism by deep-sea water in cultured human liver (HepG2) cells. Mar. Biotechnol., 16, 219-229 (2014).

11) Ha BG, Park JE, Shin EJ, Shon YH. Effects of balanced deep-sea water on adipocyte hypertrophy and liver steatosis in high-fat, dietinduced obese mice. Obesity, 22, 1669-1678 (2014).

12) Liu HY, Liu MC, Wang MF, Chen WH, Tsai CY, Wu KH, Lin CT, Shieh YH, Zeng R, Deng WP. Potential osteoporosis recovery by deep sea water through bone regeneration in SAMP8 mice. Evid. Based Complement. Alternat. Med., 2013, 161976 (2013).

13) Hataguchi Y, Tai H, Nakajima H, Kimata H. Drinking deep-sea water restores mineral imbalance in atopic eczema/dermatitis syndrome. Eur. J. Clin. Nutr., 59, 1093-1096 (2005).

14) Hou CW, Tsai YS, Jean WH, Chen CY, Ivy JL, Huang CY, Kuo $\mathrm{CH}$. Deep ocean mineral water accelerates recovery from physical fatigue. J. Int. Soc. Sports Nutr., 10, 7 (2013).

15) Fan H, Tan Z, Hua Y, Huang X, Gao Y, Wu Y, Liu B, Zhou Y. Deep sea water improves exercise and inhibits oxidative stress in a physical fatigue mouse model. Biomed. Rep., 4, 751-757 (2016).

16) Yang CC, Yao CA, Lin YR, Yang JC, Chien CT. Deep-sea water containing selenium provides intestinal protection against duodenal ulcers through the upregulation of $\mathrm{Bcl}-2$ and thioredoxin reductase 1. PLOS ONE, 9, e96006 (2014).

17) Kim S, Chun SY, Lee DH, Lee KS, Nam KS. Mineral-enriched deep-sea water inhibits the metastatic potential of human breast cancer cell lines. Int. J. Oncol., 43, 1691-1700 (2013).

18) Yoshioka S, Hamada A, Cui T, Yokota J, Yamamoto S, Kusunose M, Miyamura M, Kyotani S, Kaneda R, Tsutsui Y, Odani K, Odani I, Nishioka Y. Pharmacological activity of deep-sea water: examination of hyperlipemia prevention and medical treatment effect. Biol. Pharm. Bull., 26, 1552-1559 (2003).

19) Miyamura M, Yoshioka S, Hamada A, Takuma D, Yokota J, Kusunose M, Kyotani S, Kawakita H, Odani K, Tsutsui Y, Nishioka Y. Difference between deep seawater and surface seawater in the preventive effect of atherosclerosis. Biol. Pharm. Bull., 27, 1784-1787 (2004).

20) Matsuda A, Kumadani S, Kataoka M, Sato M, Kimura M, Itokawa Y. Effects of an essential trace element agent (TE-5) for total parenteral nutrition on the mineral nutrition in rats fed a trace elementdeficient diet. Nippon Eiseigaku Zasshi, 47, 695-703 (1992).

21) Chiba H, Takasaki M, Masuyama R, Uehara M, Kanke Y, Suzuki $\mathrm{K}$, Goto S. Time course of change in hepatic lipid peroxide level in iron-deficient rats. Journal of Japanese Society of Food and Nutrition, 51, 201-206 (1998). 
22) Yokoi K, Kimura M, Itokawa Y. Effect of copper- or iron-deficiency on nutritional status of copper and iron in rats. Biomed. Res. On Trace Elements, 1, 109-110 (1990).

23) Kodama H. Essential rtace elements and immunity. Nippon Rinsho, 54, 46-51 (1996).

24) Kitagishi Y, Kobayashi M, Yamashina Y, Matsuda S. Elucidating the regulation of $\mathrm{T}$ cell subsets. Int. J. Mol. Med., 30, 1255-1260 (2012).

25) Orihara K, Nakae S, Pawankar R, Saito H. Role of regulatory and proinflammatory T-cell populations in allergic diseases. World $\mathrm{Al}$ lergy Organ J., 1, 9-14 (2008)

26) Marzullo L, Tosco A, Capone R, Andersen HS, Capasso A, Leone A. Identification of dietary copper- and iron-regulated genes in rat intestine. Gene, 338, 225-233 (2004).

27) Watanabe K, Tanaka R, Akisue S, Yoshikawa Y, Orino K. Assessment of absorption of iron sesquioxide in rats with iron deficiency anemia. J. New Rem. \& Clin., 59, 1127-1132 (2010).

28) Arai $T$, Nakamura $K$, Muto M, Fujii $S$, Murata $T$. Effects of inspissated mineral water from deep sea water for experimental life habitual disease model rats. Japanese Journal of Medicine and Pharmaceutical Science, 50, 787-793 (2003).

29) Ogata F, Nagai N, Ito Y, Kawasaki N. Fundamental study on effect of high-mineral drinking water for osteogenesis in calciprivia ovari- ectomized rats. Journal of the Pharmaceutical Society of Japan, 134, 679-685 (2014).

30) Monobe M, Ema K, Tokuda Y, Maeda-Yamamoto M. Effect on the epigallocatechin gallate/epigallocatechin ratio in a green tea $\mathrm{Ca}-$ mellia sinensis L.) extract of different extraction temperatures and its effect on IgA production in mice. Biosci. Biotechnol. Biochem., 74, 2501-2503 (2010).

31) Hughes S, Kelly P. Interactions of malnutrition and immune impairment, with specific reference to immunity against parasites. Parasite Immunol., 28, 577-588 (2006).

32) Hassan TH, Badr MA, Karam NA, Zkaria M, El Saadany HF, Abdel Rahman DM, Shahbah DA, Al Morshedy SM, Fathy M, Esh $\overline{A M}$, Selim AM. Impact of iron deficiency anemia on the function of the immune system in children. Medicine, 95, e5395 (2016).

33) Nomura I, Morita H, Maeda H, Kurashige T, Tanabe S, Yamaguchi M, Tamura M, Kawakita H. The effect of deep sea water on the treatment of atopic dermatitis. Japanese Journal of Pediatrics, $\mathbf{4 8}$, 2251-2256 (1995).

34) Tsuchiya $Y$, Nakamura $K$, Sekikawa $H$, Kawamura H, Miyanishi $\mathrm{K}$, Ishizu T, Yamamoto M. Subacute effects of deep-sea water from the Japan Sea on blood examination values in mice. Environ. Health Prev. Med., 7, 189-192 (2002). 